\title{
Building and Burying Fear Memories in the Brain
}

STEPHEN MAREN

University of Michigan

\begin{abstract}
The world is a dangerous place. Whether this danger takes the form of an automobile careening toward you or a verbal threat from a stranger, your brain is highly adapted to perceive such threats, organize appropriate defensive behaviors, and record the circumstances surrounding the experience. Indeed, memories of fearful events serve a critical biological function by allowing humans and other animals to anticipate future dangers. But these memories can also feed pathological fear, yielding crippling clinical conditions such as panic disorder. In this review, the author will examine how the brain builds fear memories and how these memories come to be suppressed when they no longer predict danger. The review will focus on the fundamental role for synapses in the amygdala in acquiring fear memories and the function of neural circuits interconnecting the amygdala, hippocampus, and prefrontal cortex in modulating the expression of such memories once learned. The discovery of the neural architecture for fear memory highlights the powerful interplay between animal and human research and the promise for understanding the neurobiological mechanisms of other complex cognitive phenomena. NEUROSCIENTIST 11(1):89-99, 2005. DOI: $10.1177 / 1073858404269232$
\end{abstract}

KEY WORDS Amygdala, Long-term potentiation (LTP), Hippocampus, Pavlovian conditioning, Extinction

We all have fears, whether they are conjured by hairylegged insects stalking us under our bed sheets, shiny needles breaching our bulging veins, or abusive bullies that use pain and intimidation to make us submit. In most, if not all, cases, these fears are learned. They are manifestations of core memories that we carry with us to work, to school, to a friend's home for dinner, and to sleep at night. Fortunately, however, fear memories are often silent, lurking beneath the surface of consciousness and waiting for a certain messenger to call them forth. Once called, these memories mobilize an impressive response of bodily changes that include, as we all know, a racing heart, sweaty palms, and an inescapable feeling of dread. This is surely unpleasant - but eminently adaptive - most of the time.

In some cases, the brain's defensive system, which was designed to protect us from danger, works too well. Memories of intense trauma, such as combat or sexual assault, breach the surface of consciousness regularly and intrusively. Even signals only weakly reminiscent of the original trauma come to harness the fear response, and they fail to yield this power despite their repeated failure to predict true danger. The autonomic signature of fear may itself come to precipitate a full-blown fear response, as in patients with panic disorder who come to have panic attacks when they detect only the slightest hiccup in their beating heart. In all of these cases, fear memories engender a debilitating pathological state that has dire consequences for the victim's quality of life.

It is not so surprising, then, that recent years have seen a surge in interest in the psychological and neurobiolog-

Address correspondence to: Stephen Maren, Department of Psychology, University of Michigan, 525 E. University Ave., Ann Arbor, MI 48109-1109 (e-mail: maren@umich.edu). ical mechanisms underlying fear memory. This work has been fueled by the neuroscientific analysis of wellcharacterized forms of fear learning. This analysis has its roots in animal models but has more recently been applied to humans. As a matter of fact, the advent of modern functional neuroimaging techniques has allowed an unprecedented analysis of fear learning in both normal individuals and patients with anxiety disorders.

\section{Pavlovian Fear Conditioning: A Model System}

In the laboratory, the neurobiological analysis of fear has relied on a procedurally simple form of learning called Pavlovian fear conditioning. In this form of learning, rats or humans learn that an innocuous stimulus (the conditional stimulus [CS]) predicts the occurrence of a different, noxious stimulus (the unconditional stimulus [US]). In a rat, one might use an electric foot shock as the US, whereas in a human subject, the US might be a loud noise or a wrist shock. In either case, the CS comes to evoke a learned fear response (the conditional response $[\mathrm{CR}]$ ) that is manifest by a number of somatic (e.g., freezing) and autonomic (e.g., rapid heart beat) responses.

The laboratory procedure used to establish Pavlovian fear conditioning mimics the coincidence of stimuli and their (sometimes) adverse consequences in everyday life. For example, if you are tailgated by an aggressive driver in a red pickup truck (CS) and consequently run off the road into a ditch (US), then it is likely that you will be afraid (CR) when a similar red pickup truck pulls up behind you in the future. Our lives are filled with these sorts of experiences, and Pavlovian conditioning procedures are incredibly useful for modeling these experiences in the laboratory. Besides modeling "normal" fear learning, principles of Pavlovian conditioning 
are also important for understanding the psychological basis for a variety of anxiety disorders (Bouton and others 2001; Ohman and Mineka 2001).

It was appreciated many years ago that the Pavlovian conditioning paradigm is an ideal model system for analyzing the neural substrates of memory formation (Hawkins and Kandel 1984; Byrne 1987; Thompson 1988). Using this approach, several investigators began mapping the neuroanatomy of fear in the mammalian brain in the late 1970s and early 1980s. Pioneers in the field include Bruce Kapp, Phillip McCabe, and Neil Schneiderman, who pursued the neural circuits underlying the conditioning of cardiovascular responses in rabbits (Kapp and others 1979; Jarrell and others 1986); Joseph LeDoux and David Cohen, who examined these responses in rats and pigeons, respectively (Cohen 1975; LeDoux and others 1984); and Michael Davis, who mapped the neural circuitry underlying fear-potentiated acoustic startle responses in rats (Davis and others 1982). All of these investigators converged on the conclusion that the amygdala, a group of nuclei buried within the temporal lobes, is central to learning and remembering fearful experiences.

\section{All Roads Lead to the Amygdala}

The amygdala is without question the neuroanatomical center of the fear memory universe. Despite its small size, the amygdala has an enormous influence on emotional learning and memory (McGaugh 2004). Early clues to the role of the amygdala in fear stemmed from the work of Kluver and Bucy (1937), who found marked changes in emotional behavior, including a loss of fear, following resections of large portions of the temporal lobes in monkeys. Later work showed that the changes in emotional behavior resulted from damage to the amygdala, a collection of anatomically and functionally distinct nuclei buried deep within the temporal lobe (Meunier and others 1999; Weiskrantz 1956). Not surprisingly, an impressive corpus of work in fearconditioning paradigms has converged on the seemingly inevitable conclusion that the amygdala is also critical for learning and remembering fearful events (Fendt and Fanselow 1999; LeDoux 2000; Davis and Whalen 2001; Maren 2001).

The amygdala is composed of several anatomically and functionally distinct nuclei (Pitkanen and others 1997). These nuclei are so distinct that some have questioned the utility of an encompassing anatomical term such as amygdala or amygdaloid complex to describe this heterogeneous brain area (Swanson and Petrovich 1998). Indeed, it is clear that different regions of the amygdala have unique roles in fear conditioning and that some amygdaloid nuclei have no role in fear conditioning whatsoever (Amorapanth and others 2000; Goosens and Maren 2001; Nader and others 2001). In this review, the term amygdala will be used to point to a chunk of brain behind each ear and will not be used to imply a common function of all amygdaloid nuclei in fear.
Within the amygdala, several distinct nuclei play an important role in the acquisition and expression of fear memories (Fig. 1). These nuclei include the basolateral complex of the amygdala (BLA), which includes the lateral (LA) and basal (BA) nuclei (composed of the basolateral and basomedial nuclei), the central nucleus (CE), and the intercalated nuclei (IC). In general, synaptic connectivity is unidirectional within this amygdaloid circuit, with neurons in the BLA forming excitatory synapses directly on neurons in the lateral and medial divisions of the CE. Importantly, Pare and colleagues have revealed a significant role for the intercalated nuclei in directing information flow between the BLA and CE (Royer and others 1999). This work shows that substantial lateral inhibition between clusters of inhibitory interneurons within the IC allows BLA neurons to indirectly excite neurons in the medial division of the central nucleus (CEm), the main output of the amygdala.

In addition to the extensive intrinsic connections within the amygdala, the synaptic connectivity of BLA and $\mathrm{CE}$ with other areas of the brain is incredibly diverse (Fig. 2). Sensory information from the thalamus, including the medial geniculate nucleus and posterior intralaminar thalamic complex, converges in the CE and BLA (LeDoux, Farb, and others 1990; Doron and LeDoux 2000; Pare and others 2004). Neurons in the BLA receive considerable cortical and hippocampal input (McDonald 1998), and within the BLA, the lateral nucleus of the amygdala (LA) appears to be the primary site for convergence and association of CS and US information (Fig. 2). The hippocampal formation transmits multimodal information concerning the contexts that define the time and place of aversive experiences (O'Reilly and Rudy 2001; Sanders and others 2003) to both LA and BA. Highly processed information also reaches the amygdala through its connections with several frontal cortical regions including the prefrontal cortex (McDonald 1998). And information concerning foot shock USs may reach LA via axons passing near the posterior intralaminar thalamic complex (Lanuza and others 2004; Pare and others 2004).

Fear responses are mediated by a host of brain areas involved in cardiovascular and respiratory regulation, immobility and analgesia, release of stress hormones, and acoustic startle, among others (LeDoux and others 1988; Davis 1992; Maren and Fanselow 1996). For example, foot shock USs generate activity bursts and vocalization through projections to the dorsal periaqueductal gray (PAG). In contrast, fear CSs, including tones and contexts, come to evoke freezing through projections from CEm to the ventral PAG. The central nucleus also projects to several other hypothalamic, midbrain, and medullary nuclei to organize an integrated fear response to stimuli that signal threat. In addition to coordinating fear responses, it is important to note that the $\mathrm{CE}$ is also a source for convergence of CS and US information and, like the BLA, may be involved in associative plasticity related to fear learning (Pare and others 2004). 


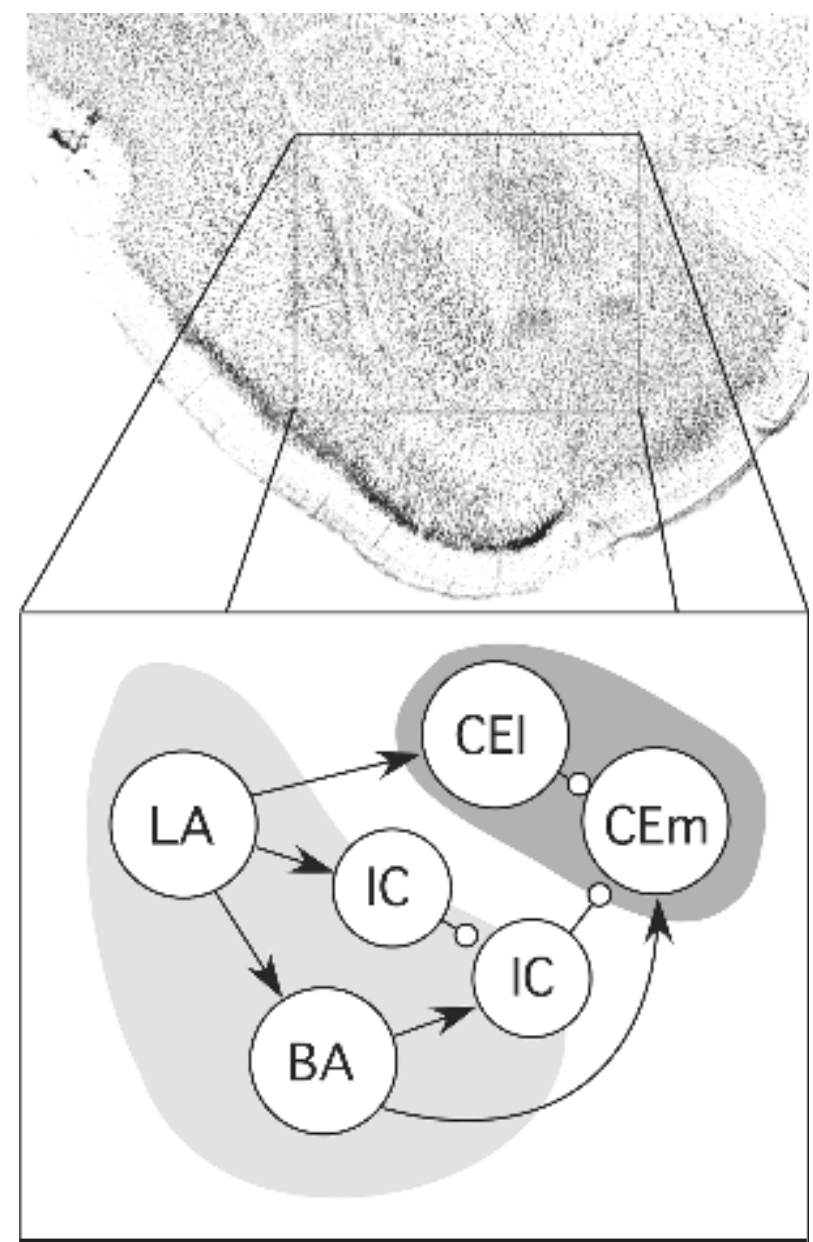

Fig. 1. Intrinsic circuitry of the amygdaloid nuclei involved in Pavlovian fear conditioning. The thionin-stained coronal section from rat brain shows the location of the amygdaloid nuclei involved in fear conditioning, and the inset indicates the relevant intrinsic circuits interconnecting these nuclei. Information cascades from the basolateral complex (light gray) to the central nucleus (dark gray). Excitatory projections are indicated by arrowheads and inhibitory projections by open circles. LA = lateral nucleus; $\mathrm{BA}=$ basal nuclei (including the basolateral and basomedial nuclei); IC = intercalated nuclei; CE = central nucleus, including lateral (CEI) and medial (CEm) divisions.

\section{Without You I Am Not Afraid}

The connectional anatomy of the amygdaloid complex clearly suggests that it might serve as an interface between sensory inputs transmitting information about the time, place, and nature of biologically relevant stimuli and motor outputs regulating somatic and autonomic responses engaged during fear. Indeed, a central role for the amygdaloid nuclei in Pavlovian fear conditioning has been demonstrated by numerous studies (Fendt and Fanselow 1999; LeDoux 2000; Davis and Whalen, 2001; Maren 2001). The bulk of this evidence has been derived from animals with experimentally induced brain damage. Early studies reported that large lesions of the amygdaloid complex that included several amygdaloid nuclei and damaged passing axons impair the acquisition of conditioned fear responses, such as bar press sup- pression (Kellicutt and Schwartzbaum 1963) and freezing (Blanchard and Blanchard 1972). Subsequent work reproduced these behavioral outcomes with smaller lesions limited to the central (Hitchcock and Davis 1986) or lateral (LeDoux, Cicchetti, and others 1990) nuclei. More recent work using neurotoxic agents has confirmed that damage to neurons (as opposed to the combined loss of neurons and passing axons) in the lateral, central, and basolateral (in some cases) nuclei prevents fear learning (Campeau and Davis 1995; Maren, Aharonov, and Fanselow 1996; Goosens and Maren 2001).

In addition to preventing learning (i.e., acquiring new fears), amygdala lesions also abolish fear memory (i.e., expression of old fears). For example, neurotoxic lesions of the basolateral complex or central nucleus abolish the expression of conditional fear responses when made weeks or months after conditioning or after extensive overtraining (Lee and others 1996; Maren, Aharonov, and Fanselow 1996; Maren 1998, 1999b; Gale and others 2004). Importantly, these deficits are not secondary to lesion-induced changes in motor performance, sensory processing, or emotionality (Campeau and Davis 1995; Maren 1998). For instance, freezing behavior elicited by predator odors or after copulation is normal in rats with amygdala lesions (Wallace and Rosen 2001; Choi and Brown 2003) or after amygdala inactivation (Fendt and others 2003). In addition, rats with amygdala lesions exhibit normal behavior in several tests of unconditioned anxiety (Treit and Menard 1997; McHugh and others 2004). And with extensive training, rats with basolateral amygdala lesions will ultimately exhibit conditional fear responses including freezing, suggesting that their capacity to exhibit fear and freezing is intact under some conditions (Maren 1999b).

Although experimentally induced brain damage is an essential tool for defining the neural circuits mediating learning and memory, extreme care must be exercised in dissociating the effects of brain lesions on learning versus performance (Cahill and others 2001). An alternative to permanent brain lesions is achieved by using microinfusions of various pharmacological agents to temporarily inactivate discrete brain regions. Using these procedures, temporary inactivation of the amygdala with lidocaine (a voltage-gated sodium channel blocker; Helmstetter 1992), GABA receptor agonists (e.g., muscimol; Helmstetter and Bellgowan 1994; Wilensky and others 1999; Maren and others 2001), or glutamate receptor antagonists (e.g., aminophosphonovaleric acid [APV], an $\mathrm{N}$-methyl-D-aspartate [NMDA] receptor antagonist; Miserendino and others 1990; Maren, Aharonov, Stote, and others 1996; Lee and Kim 1998; Fendt 2001; Goosens and Maren 2003; Lindquist and Brown 2004) also demonstrate a critical role for the amygdala in the acquisition and expression of fear memories.

Based on these results and the connectional anatomy of the amygdala, a simple model of fear conditioning has been proposed (Fendt and Fanselow 1999; LeDoux 2000; Davis and Whalen 2001; Maren 2001). The model assigns associative functions (i.e., learning and remem- 

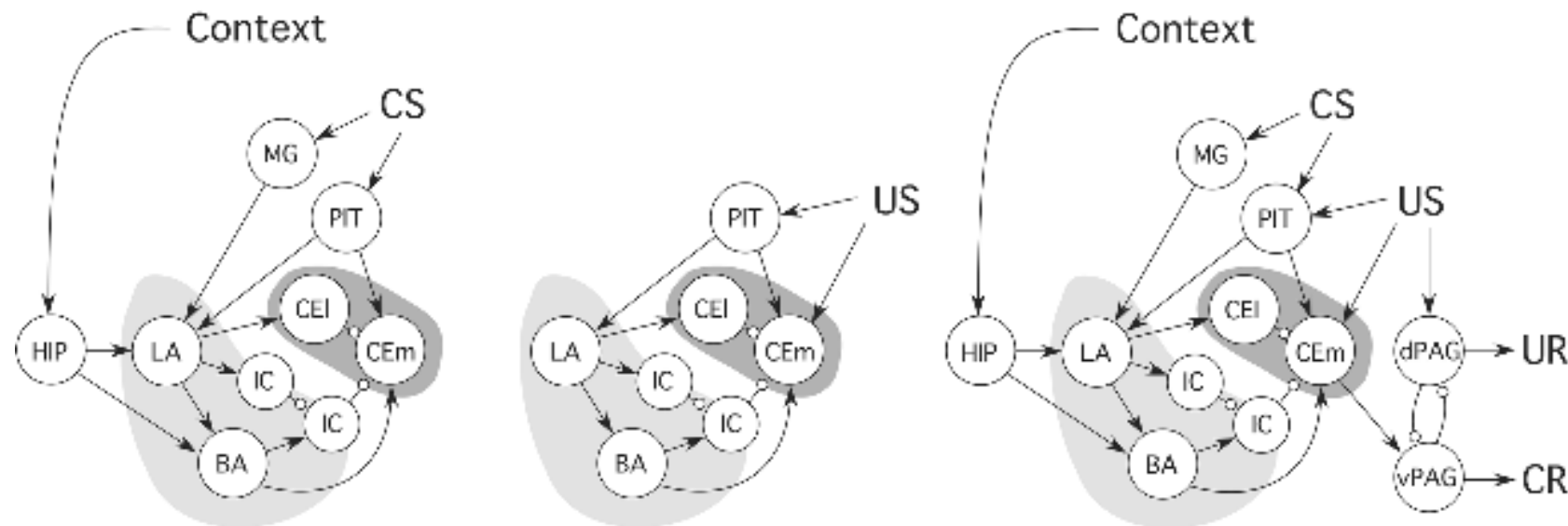

Fig. 2. Sensory and motor interfaces of the amygdala relevant to Pavlovian fear conditioning. For simplicity, the diagram focuses on the anatomy of circuits involved in processing auditory and contextual conditional stimuli (CSs) and foot shock unconditional stimuli (USs) and builds on the intrinsic connectivity of the amygdala indicated in Figure 1. Auditory information reaches the lateral nucleus (LA) by way of the thalamic medial geniculate nucleus (MG) and posterior intralaminar thalamic complex (PIT); contextual stimuli reach LA and the basal nuclei (BA) via the hippocampus (HIP). Foot shock information reaches LA via the thalamus (PIT), which also projects directly to the medial division of the central nucleus (CEm). Conditional fear (CR) to foot shock, in this case freezing, is mediated by projections of CEm to the ventral periaqueductal gray (vPAG), whereas unconditioned fear responses (URs) to the shock (i.e., activity burst and vocalization) are mediated by the dorsal PAG (dPAG). Excitatory projections are indicated by arrowheads and inhibitory projections by open circles. $\mathrm{IC}=$ intercalated nuclei; $\mathrm{CEI}=$ lateral division of the central nucleus.

bering the link between CS and US) to the BLA, particularly the LA, and performance functions (i.e., generating learned fear responses) to CE. However, recent studies suggest that rather than merely coordinating fear responses as previously believed, the CE might mediate some aspects of fear learning (Killcross and others 1997; Goosens and Maren 2003). Indeed, Pare and colleagues (2004) have "rewired" the amygdaloid fear circuit and have suggested that synaptic plasticity in both the LA and $\mathrm{CE}$ is critical for normal fear learning and memory. These parallel pathways in the amygdala may contribute to distinct aspects of aversively motivated learning (Amorapanth and others 2000; Cardinal and others 2002). Nevertheless, the inescapable conclusion from this work is that neurons in the amygdala are critical for both learning and remembering fear memories.

The important role for the amygdala in fear conditioning is not limited to rats and rabbits. Indeed, humans with amygdala pathology also exhibit deficits in Pavlovian fear conditioning. These patients do not exhibit conditioned galvanic skin responses (sweating) to visual or auditory CSs paired with aversive noises or shock (Bechara and others 1995; LaBar and others 1995). An interesting observation in these patients is their normal recollection, an index of declarative or explicit memory, of the circumstances surrounding fear conditioning. That is, they can report that visual cues were paired with shock, for example, but do not manifest this conscious recollection of training in a fear CR, despite exhibiting normal unconditional responses to the aversive US (Bechara and others 1995). This suggests that amygdala damage does not eliminate memory for every aspect of an aversive experience (Vazdarjanova and McGaugh 1998) but does disrupt the memory required for fear signals to marshal autonomic and somatic responses (such as sweating) to those signals. In addition to harboring fear memories, the amygdala also plays an important role in modulating the storage of emotional memories in other brain areas during aversive experiences (McGaugh 2004). Thus, amygdala neurons store some aspects of fear memory and facilitate the storage of other aspects of fear memory in other areas of the brain.

\section{Neuronal Signals for Fear Memory}

The important role for amygdala neurons in fear conditioning is also reflected in their activity patterns. In human neuroimaging experiments, for example, Pavlovian CSs increase regional cerebral blood flow in the amygdala (Buchel and others 1998; LaBar and others 1998; Morris and others 1998; Cheng and others 2003). These increases are most pronounced early in fear conditioning and during early phases of extinction testing, suggesting that the amygdala may be particularly tuned to changes in the relevance of stimuli (Buchel and Dolan 2000; Calder and others 2001). Nonetheless, per- 
sistent changes in fear-related activity have been described in the amygdala even after a fear stimulus $(\mathrm{CS}+)$ no longer predicts an aversive outcome (Morris and Dolan 2004). This suggests that the amygdala may store fear memories, even when the aversive outcome that generated the fear memory in the first place no longer occurs.

Human neuroimaging experiments validate the important role for the amygdala in fear conditioning but yield little information concerning the precise spatial localization and temporal dynamics of neuronal activity within the amygdaloid complex during fear learning. This problem is overcome, however, with the advent of sophisticated neuronal recording techniques in animals. It is now possible to record the activity of several amygdala neurons simultaneously (parallel single-unit recordings) from discrete amygdaloid nuclei with temporal resolutions on the scale of milliseconds. Recent work using these techniques reveals that single neurons within LA exhibit robust changes in activity during fear conditioning (Quirk and others 1995; Maren 2000; Pare and Collins 2000). More specifically, pairing an auditory stimulus, such as a pure tone or white noise, with foot shock greatly increases the number of action potentials evoked by that auditory stimulus among LA neurons. These changes in LA occur at short latencies (even after overtraining), revealing that they originate in auditory projections from the thalamus (rather than the auditory cortex). However, the learning-related changes in LA spike firing are not passively relayed from the thalamus because neuronal plasticity in the thalamus is itself dependent on the amygdala (Maren and others 2001; Poremba and Gabriel 2001).

But do conditioning-induced changes in lateral amygdala spike firing represent fear memory? In other words, might the changes in neuronal activity in the amygdala that accompany fear conditioning be a consequence of fear, rather than its cause? Recent work addresses this important issue by showing that the expression of fear alone is not sufficient to reproduce the pattern of neuronal activity associated with fear conditioning (Goosens and others 2003). In this study, rats were trained using a differential fear-conditioning paradigm, in which one $\mathrm{CS}$ (the $\mathrm{CS}+$ ) predicted the US, whereas the other CS (the CS-) did not. Neurons in LA developed increases in spike firing to the CS+ but not the CS(Collins and Pare 2000), and the rats exhibited fear responses only to the CS+. Importantly, masking the behavioral discrimination by testing rats to both CSs in an aversive context did not attenuate the neuronal discrimination. In other words, LA neurons continue to differentiate the associative history of the CSs, even when the animal's fear was held constant during CS presentations. Moreover, disabling fear responses by inactivating $\mathrm{CE}$ did not eliminate the conditioning-related changes in spike firing in LA (Goosens and others 2003). Hence, the behavioral expression of fear is neither necessary nor sufficient for associative spike firing in LA. Neuronal activity in LA codes memories for aversive experiences and is not simply a consequence of being afraid.

\section{It's All About Change}

The definition of the essential neural circuit for fear conditioning in the amygdala is important because it permits the analysis of the cellular events underlying memory storage in amygdala neurons. The most promising cellular mechanism for memory storage in the mammalian brain is LTP, which is an enduring enhancement in synaptic transmission that exhibits several properties suitable for storing information (Maren and Baudry 1995; Martin and others 2000). There is now substantial evidence suggesting that LTP at excitatory synapses in the amygdala may mediate long-term fear memories (Maren 1999a; Blair and others 2001; Schafe and others 2001; Goosens and Maren 2002). Although first described in the hippocampus by Bliss and Lomo (1973), there is now substantial evidence that amygdala neurons exhibit LTP (Maren 1996). In intact animals, LTP can be induced in the BLA after high-frequency stimulation of the auditory thalamus or auditory cortex in vivo (Yaniv and others 2001; Doyere and others 2003). Electrical stimulation of the hippocampal formation or entorhinal cortex also induces LTP in the basal nuclei (Maren and Fanselow 1995; Yaniv and others 2001). Brain slice preparations have also revealed synaptic plasticity in several amygdaloid nuclei (Chapman and others 1990; Heinbockel and Pape 2000; Royer and Pare 2003). These studies suggest that amygdala neurons possess the fundamental synaptic and cellular machinery to support long-term synaptic plasticity.

The involvement of LTP in fear conditioning is supported by a number of pieces of evidence (Maren 1999a; Blair and others 2001; Schafe and others 2001; Goosens and Maren 2002). In studies that bridge behavior and electrophysiology, it has been shown that fear conditioning in behaving animals augments synaptic potentials in amygdala slices obtained from these animals after conditioning (McKernan and Shinnick-Gallagher 1997). The conditioning-induced change in amygdalar synaptic transmission is mediated by both increases in presynaptic transmitter release and postsynaptic changes in NMDA receptor function (Tsvetkov and others 2002; Zinebi and others 2003). Accordingly, behavioral conditioning also occludes LTP induction and the alteration in presynaptic transmitter release that accompanies fear learning (Tsvetkov and others 2002). Similar results have been demonstrated in intact animals. For example, it has been shown that both LTP induction in the auditory thalamus and fear conditioning augment auditoryevoked responses in the lateral amygdala (Rogan and LeDoux 1995; Rogan and others 1997). The electrophysiological changes in both cases are remarkably similar. Moreover, LTP in the basolateral amygdala after hippocampal formation stimulation in vivo has a presynaptic component (Maren and Fanselow 1995). These results suggest that behavioral learning and experimentally induced LTP produce isomorphic changes at amygdala synapses.

Because single neurons in the lateral amygdala respond to both CSs and USs (Romanski and others 
1993), it has been postulated that the convergence of this information on single amygdala neurons promotes Hebbian synaptic plasticity at sensory afferents in the amygdala to yield fear CRs. Recent work suggests that LTP in the amygdala, like that in the hippocampus, exhibits Hebbian associativity and can be induced by pairing weak presynaptic stimulation (modeling the CS) with strong postsynaptic depolarization (modeling the US). LTP induced in this way is sensitive to the contingency of presynaptic and postsynaptic activity (Bauer and others 2001). That is, postsynaptic depolarization in the absence of concomitant presynaptic activity degrades established LTP in a way that parallels the effects of noncontingent shock presentations on fear conditioning.

Of course, some of the earliest evidence suggesting a role for amygdaloid LTP in fear conditioning came from pharmacological work. In a pioneering study, Miserendino and colleagues (1990) found that microinfusions of the NMDA receptor antagonist APV into the basolateral amygdala disrupted the acquisition, but not expression, of fear-potentiated startle. Later work extended this finding, and several studies have now shown that infusions of NMDA receptor antagonists into the amygdala retard fear conditioning (Campeau and others 1992; Fanselow and Kim 1994; Maren, Aharonov, Stote, and others 1996; Lee and Kim 1998; Walker and Davis 2000). However, a number of these studies report that APV also impairs the expression of existing fear memories (Maren, Aharonov, Stote, and others 1996; Lee and Kim 1998; Fendt 2001; Lindquist and Brown 2004), which is consistent with the reduction in cell excitability in the amygdala produced by APV (Li and others 1995; Maren and Fanselow 1995). Thus, it is not clear whether the effects of APV on fear conditioning are due to a disruption of synaptic potentiation or a general decrease in cell excitability. More recently, it has been reported that drugs that preferentially antagonize a subtype of NMDA receptors containing NR2B subunits produce stronger effects on the acquisition compared to expression of conditional fear (Rodrigues and others 2002; Goosens and Maren 2004). Moreover, NMDA receptor antagonists abolish the acquisition of conditional spike firing among LA neurons, although having little effect on the expression of such activity (Goosens and Maren 2004). Hence, NMDA receptor-dependent LTP in the amygdala remains a viable mechanism for the acquisition of fear memories.

Because of the potential role of NMDA receptors in the activity of amygdala neurons, much of the recent work on the pharmacology of fear conditioning has focused on the cellular events subsequent to NMDA receptor activation. It is well established that calcium influx through active NMDA receptors and voltagegated calcium channels is essential for triggering the cellular cascades underlying long-term synaptic plasticity (Maren and Baudry 1995; Martin and others 2000). Calcium influx triggers the activation of a number of intracellular cascades that are essential for the induction of long-term synaptic plasticity. Of particular interest is the activation of protein kinases that modulate membrane-bound receptors and channels, including protein kinase $\mathrm{A}$, protein kinase $\mathrm{C}$, and calcium-calmodulin kinase II, and other kinases, such as mitogen-activated kinase (MAPK) and MAPK kinase, that constitute a critical pathway regulating transcriptional factors including CREB (Thomas and Huganir 2004). There is now evidence that inhibiting each of these kinases in the amygdala before or shortly after fear conditioning impairs the acquisition of long-term fear memory without affecting short-term fear memory (Goosens and others 2000; Schafe and LeDoux 2000; Schafe and others 2000; Lin and others 2001; Rodrigues and others 2004). Infusions of protein synthesis inhibitors into the amygdala shortly after conditioning also yield severe retention deficits (Nader and others 2000; Schafe and LeDoux 2000; Maren and others 2003). Fear conditioning is associated with phosphorylation of MAPK and CREB induction (Atkins and others 1998; Impey and others 1998; Schafe and others 2000), which are presumably mediated by activity in the Ras-MAPK pathway coupled to NMDA receptor activation (Krapivinsky and others 2003). Overexpression of CREB in the amygdala also enhances fear conditioning (Josselyn and others 2001). In support of this possibility, genetically modified animals with disrupted Ras-MAPK signaling exhibit impaired amygdala LTP and fear conditioning (Brambilla and others 1997), whereas those with enhanced signaling in this pathway exhibit augmented amygdaloid LTP and fear conditioning (Dhaka and others 2003). Hence, there exists an intricate network of signaling cascades in the amygdala that are critical for establishing long-term synaptic plasticity and fear memory.

\section{Breaking the Fear}

A strong case has been made that long-term memories for Pavlovian fear conditioning, at least those that support fear CRs, are mediated by synaptic plasticity in the amygdala. By this view, then, building fear memories requires long-term synaptic modifications within the amygdala. And given that the amygdala is involved in maintaining Pavlovian fear memories for almost the entire adult life span of a rat (Gale and others 2004), it appears that these memories and their synaptic correlates reside in the amygdala permanently. The identification of the cellular mechanisms for building a fear memory is of paramount importance in understanding the neurobiological basis of fear memory and disorders of fear and anxiety that may involve aberrations in such memories. Of course, an equally important issue with considerable clinical relevance is how to suppress or eliminate fear memories after they are learned.

A behavioral phenomenon that has received considerable interest in this regard is extinction, which is the loss of conditional responding (in this case loss of fear CRs) that occurs after presentations of a CS in the absence of the US. Extinction was first described by Pavlov (1927) and has since received considerable experimental attention (Bouton 1993; Quirk 2001; Myers and Davis 2002). 
Importantly, there is a large volume of data indicating that extinction is itself new learning (in this case inhibitory learning) that comes to inhibit the expression of Pavlovian CRs (Bouton 1993). And unlike the excitatory memories established through conditioning, the inhibitory memories established through extinction procedures tend to be relatively labile. That is, extinction fades over time, promoting the spontaneous recovery of excitatory CRs as time elapses after extinction. Moreover, extinction memories are context dependent; that is, CR expression is limited only in the context in which CS-alone presentations occurred (Bouton and Bolles 1979; Harris and others 2000). After extinction, CSs will continue to evoke robust CRs when they are encountered outside of the extinction context. All of these data suggest that conditioning and extinction produce two different memories concerning the CS and US: an excitatory memory that promotes CR expression and an inhibitory memory that suppresses CR expression (Bouton 1994). In this way, extinction buries fear memory, leaving the original trace of the aversive experience intact yet quiescent.

Given the prominent role of the amygdala in fear conditioning, it represents an obvious region of interest related to the mechanisms of extinction learning. Consistent with a role for the amygdala in extinction learning, there is now substantial evidence that some of the same cellular mechanisms involved in fear conditioning are also involved in the extinction of fear memory (Myers and Davis 2002). Inhibition of NMDA receptors or MAPK in the amygdala retards extinction learning (Falls and others 1992; Lee and Kim 1998; Lu and others 2001), and enhancement of NMDA activity enhances extinction learning (Walker and others 2002). Moreover, some of the biochemical changes induced in the amygdala by conditioning appear to be reversed after extinction training (Lin and others 2003). These data suggest that neurons in the amygdala may be the locus for the inhibitory memories learned during extinction; however, they do not address how amygdala neurons maintain both excitatory and inhibitory memories after conditioning and extinction and how such memories are regulated by context, for example.

Clues to the regulation of amygdala-based memories after extinction have come from electrophysiological recording studies. This work indicates that some neurons in LA exhibit changes in spike firing over the course of extinction that correlate with the loss of fear CRs (Quirk and others 1997). Interestingly, there is another population of lateral amygdala neurons that tends to maintain high levels of CS-elicited spike firing after extinction (Repa and others 2001). This suggests that excitatory and inhibitory memories may actually be distributed among different amygdala neurons. On the other hand, recent work from our laboratory reveals that individual LA neurons can code both conditioning and extinction memories (Hobin and others 2003). That is, we have shown that single LA neurons exhibit low levels of spike firing to an extinguished CS when it is presented inside its extinction context but high levels of firing to that same CS when it is presented outside of its extinction context. In other words, LA spike firing is context dependent after extinction. This pattern of results implies that extinction may engage an inhibitory network in the amygdala to gate the expression of fear memories by shunting CS-evoked excitation in LA neurons.

The context dependence of extinction raises interesting questions concerning the locus and regulation of inhibition after extinction. Several studies indicate an important role for the prefrontal cortex in extinction. Lesions of the prefrontal cortex (Morgan and LeDoux 1995; Quirk and others 2000) or infusions of protein synthesis inhibitors into the prefrontal cortex (Santini and others 2004) retard long-term memories of fear extinction. Moreover, prefrontal cortical neurons exhibit extinction-related changes in spike firing, and pairing prefrontal cortical stimulation with auditory CSs yields behavioral extinction (Milad and Quirk 2002). These data suggest that some component of the inhibitory memory acquired during extinction learning may reside in the prefrontal cortex. This prefrontal cortical memory could come to inhibit the expression of fear CRs by exciting inhibitory interneurons in the intercalated nuclei of the amygdala, which allow LA neurons to generate fear output via the central nucleus (Quirk and others 2003; Pare and others 2004). Alternatively, prefrontal projections to LA might engage local inhibitory networks in LA to modulate fear responding (Shumyatsky and others 2002; Rosenkranz and others 2003). Of course, it is conceivable that these processes work in parallel to regulate fear responding.

Such mechanisms allow for the inhibition of fear memory after extinction but do not explain the context dependence of extinguished fear memories. Because of the prominent role of the hippocampus in processing contextual information (O'Reilly and Rudy 2001; Sanders and others 2003), we have focused on the role of the hippocampus in the context specificity of extinction memories. Using reversible hippocampal lesions, we have shown that the dorsal hippocampus is required for the context-specific expression of fear memory after extinction but not for the expression for extinction per se (Corcoran and Maren 2001). That is, inactivation of the hippocampus prior to retention testing prevents the renewal of fear to an extinguished CS when that CS is presented outside of its extinction context. After hippocampal inactivation, extinction memories come to dominate performance, suggesting that animals may emit behavior based on the net associative strengths of their excitatory and inhibitory experiences with the CS (Maren and Holt 2000).

The important role of the hippocampus in regulating the context dependence of fear memory after extinction suggests that a network involving the hippocampus, prefrontal cortex, and amygdala is engaged to regulate CR performance after extinction (Myers and Davis 2002; Hobin and others 2003; Fig. 3). One view is that extinction memories are encoded in the prefrontal cortex and/or amygdala and come under executive control by 

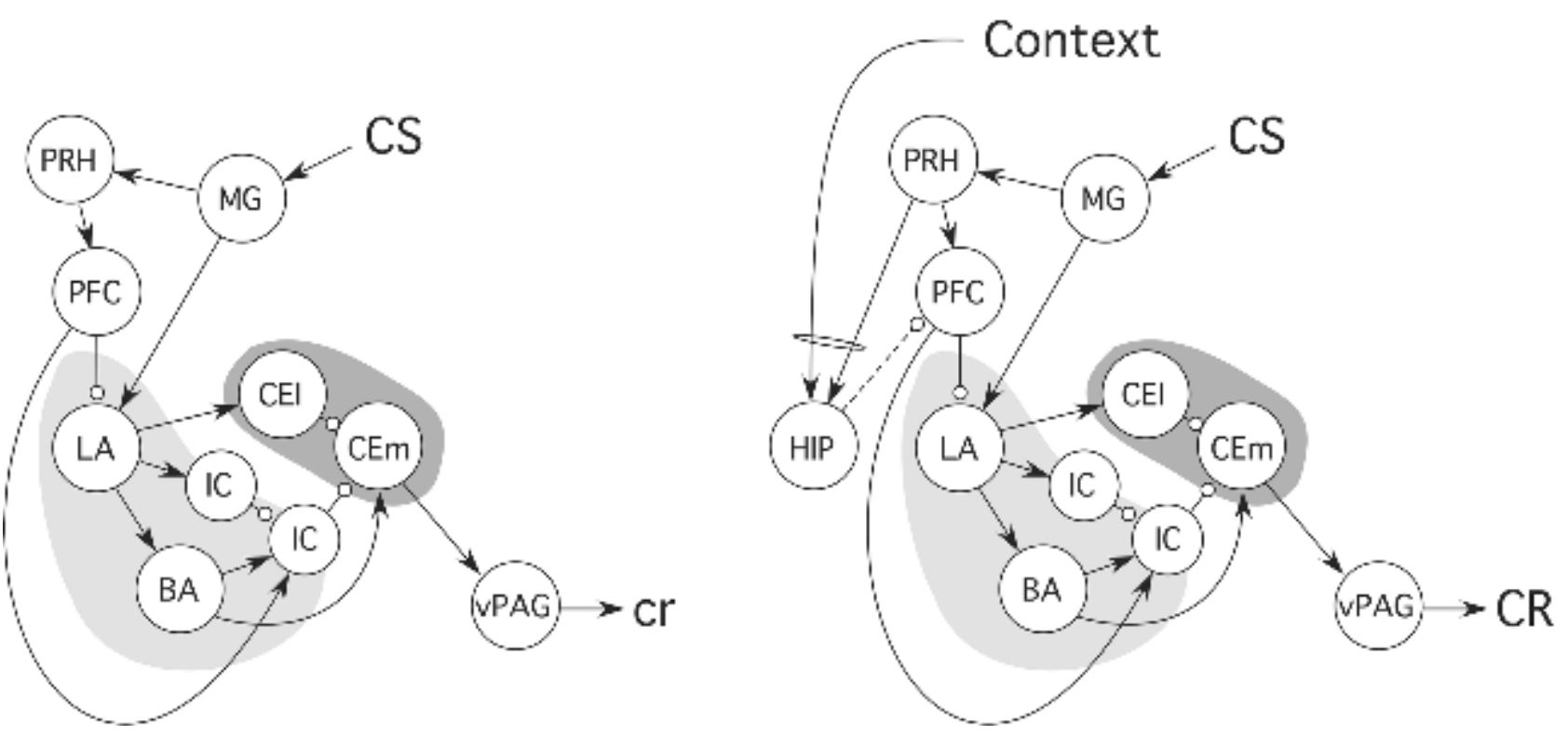

Fig. 3. Cortical and hippocampal circuitry involved in the extinction of Pavlovian fear memories. Left, Conditional stimuli (CSs) undergoing extinction recruit prefrontal cortical (PFC) and hippocampal (HIP) circuits involved in regulating fear output by the amygdala. Auditory CSs may reach the PFC via perirhinal (PRH) or primary auditory cortical projections carrying acoustic information from the auditory thalamus (MG). The PFC, in turn, may come to inhibit the amygdala (and the conditional fear responses it mediates) through inhibitory interneurons in lateral nuclei (LA) or by exciting intercalated neurons that directly inhibit output neurons in the medial division of the central nucleus (CEm). Right, The context specificity of extinction is believed to be conferred by the hippocampus. By this view, the hippocampus detects CS and context mismatches (such as when an extinguished CS is presented outside of the extinction context). Mismatch conditionally engages inhibition of the PFC circuit (dotted inhibitory connection between HIP and PFC). Inhibition of the PFC would come to reduce the inhibitory influence of the PFC on fear expression and yield a renewal of fear responding. Excitatory projections are indicated by arrowheads and inhibitory projections by open circles. $\mathrm{CEI}=$ lateral division of the central nucleus; IC = intercalated nuclei; BA = basal nuclei; vPAG = ventral periaqueductal gray; $C R$ = conditional response.

the hippocampus, which regulates activity in the prefrontal-amygdaloid circuit according to the context in which fear stimuli are encountered. In this framework, the hippocampus is involved in regulating performance to a discrete CS when that CS acquires multiple meanings (during conditioning and extinction, for example) and has a specific role in limiting the prefrontal inhibition of amygdaloid activity when an extinguished CS is presented out of context (Maren and Holt 2000; Corcoran and Maren 2001). In this model, the balance of excitation and inhibition in the fear circuit regulates performance, and the hippocampus has a specific role in promoting excitation in the amygdala to renew fear responding with changes in time or context after extinction. Importantly, the involvement of a broad neural network in the regulation of fear memory after extinction provides multiple targets for clinical interventions aimed at suppressing disorders of fear and anxiety.

\section{Conclusions}

Incredible progress has been made in identifying the neural circuits and cellular mechanisms required to build and bury fear memories in the mammalian brain.
Convergence of sensory information and synaptic plasticity in the amygdala is essential to the formation and storage of fear memories. Indeed, considerable evidence suggests that some aspects of aversive experience reside permanently in the synaptic circuitry of the amygdala. Behavioral interventions, such as extinction, do not erase fear memories but yield new, inhibitory memories that suppress these memories in a time- and contextdependent manner. Inhibitory memories acquired during extinction are encoded by the amygdala and prefrontal cortex and are regulated by the hippocampus. Identifying the brain circuits and synaptic mechanisms underlying the acquisition and extinction of Pavlovian fear conditioning promises new tools and strategies for bridling the pathological fears that foster many fear and anxiety clinical disorders.

\section{References}

Amorapanth P, LeDoux JE, Nader K. 2000. Different lateral amygdala outputs mediate reactions and actions elicited by a fear-arousing stimulus. Nat Neurosci 3:74-9.

Atkins CM, Selcher JC, Petraitis JJ, Trzaskos JM, Sweatt JD. 1998. The MAPK cascade is required for mammalian associative learning. Nat Neurosci 1:602-9. 
Bauer EP, LeDoux JE, Nader K. 2001. Fear conditioning and LTP in the lateral amygdala are sensitive to the same stimulus contingencies. Nat Neurosci 4:687-8.

Bechara A, Tranel D, Damasio H, Adolphs R, Rockland C, Damasio AR. 1995. Double dissociation of conditioning and declarative knowledge relative to the amygdala and hippocampus in humans. Science 269:1115-8.

Blair HT, Schafe GE, Bauer EP, Rodrigues SM, LeDoux JE. 2001. Synaptic plasticity in the lateral amygdala: a cellular hypothesis of fear conditioning. Learn Mem 8:229-42.

Blanchard DC, Blanchard RJ. 1972. Innate and conditioned reactions to threat in rats with amygdaloid lesions. J Comp Physiol Psychol 81:281-90.

Bliss TV, Lomo T. 1973. Long-lasting potentiation of synaptic transmission in the dentate area of the anaesthetized rabbit following stimulation of the perforant path. J Physiol (Lond) 232:331-56.

Bouton ME. 1993. Context, time, and memory retrieval in the interference paradigms of Pavlovian learning. Psychol Bull 114:80-99.

Bouton ME. 1994. Context, ambiguity, and classical conditioning. Curr Dir Psychol Sci 3:49-53.

Bouton ME, Bolles RC. 1979. Contextual control of the extinction of conditioned fear. Learn Motiv 10:445-66.

Bouton ME, Mineka S, Barlow DH. 2001. A modern learning theory perspective on the etiology of panic disorder. Psychol Rev 108:4-32.

Brambilla R, Gnesutta N, Minichiello L, White G, Roylance AJ, Herron CE, and others. 1997. A role for the Ras signalling pathway in synaptic transmission and long-term memory. Nature 390:281-6.

Buchel C, Dolan RJ. 2000. Classical fear conditioning in functional neuroimaging. Curr Opin Neurobiol 10:219-23.

Buchel C, Morris J, Dolan RJ, Friston KJ. 1998. Brain systems mediating aversive conditioning: an event-related fMRI study. Neuron 20:947-57.

Byrne JH. 1987. Cellular analysis of associative learning. Physiol Rev 67:329-439.

Cahill L, McGaugh JL, Weinberger NM. 2001. The neurobiology of learning and memory: some reminders to remember. Trends Neurosci 24:578-81.

Calder AJ, Lawrence AD, Young AW. 2001. Neuropsychology of fear and loathing. Nat Rev Neurosci 2:352-63.

Campeau S, Davis M. 1995. Involvement of the central nucleus and basolateral complex of the amygdala in fear conditioning measured with fear-potentiated startle in rats trained concurrently with auditory and visual conditioned stimuli. J Neurosci 15:2301-11.

Campeau S, Miserendino MJ, Davis M. 1992. Intra-amygdala infusion of the N-methyl-D-aspartate receptor antagonist AP5 blocks acquisition but not expression of fear-potentiated startle to an auditory conditioned stimulus. Behav Neurosci 106:569-74.

Cardinal RN, Parkinson JA, Hall J, Everitt BJ. 2002. Emotion and motivation: the role of the amygdala, ventral striatum, and prefrontal cortex. Neurosci Biobehav Rev 26:321-52.

Chapman PF, Kairiss EW, Keenan CL, Brown TH. 1990. Long-term synaptic potentiation in the amygdala. Synapse 6:271-8.

Cheng DT, Knight DC, Smith CN, Stein EA, Helmstetter FJ. 2003. Functional MRI of human amygdala activity during Pavlovian fear conditioning: stimulus processing versus response expression. Behav Neurosci 117:3-10.

Choi JS, Brown TH. 2003. Central amygdala lesions block ultrasonic vocalization and freezing as conditional but not unconditional responses. J Neurosci 23:8713-21.

Cohen DH. 1975. Involvement of the avian amygdalar homologue (archistriatum posterior and mediale) in defensively conditioned heart rate change. J Comp Neurol 160:13-35.

Collins DR, Pare D. 2000. Differential fear conditioning induces reciprocal changes in the sensory responses of lateral amygdala neurons to the CS+ and CS-. Learn Mem 7:97-103.

Corcoran KA, Maren S. 2001. Hippocampal inactivation disrupts contextual retrieval of fear memory after extinction. $J$ Neurosci 21:1720-6.

Davis M. 1992. The role of the amygdala in fear and anxiety. Annu Rev Neurosci 15:353-5.
Davis M, Gendelman DS, Tischler MD, Gendelman PM. 1982. A primary acoustic startle circuit: lesion and stimulation studies. J Neurosci 2:791-805.

Davis M, Whalen PJ. 2001. The amygdala: vigilance and emotion. Mol Psychiatry 6:13-34.

Dhaka A, Costa RM, Hu H, Irvin DK, Patel A, Kornblum HI, and others. 2003. The RAS effector RIN1 modulates the formation of aversive memories. J Neurosci 23:748-57.

Doron NN, LeDoux JE. 2000. Cells in the posterior thalamus project to both amygdala and temporal cortex: a quantitative retrograde double-labeling study in the rat. J Comp Neurol 425:257-74.

Doyere V, Schafe GE, Sigurdsson T, LeDoux JE. 2003. Long-term potentiation in freely moving rats reveals asymmetries in thalamic and cortical inputs to the lateral amygdala. Eur J Neurosci $17: 2703-15$.

Falls WA, Miserendino MJ, Davis M. 1992. Extinction of fear-potentiated startle: blockade by infusion of an NMDA antagonist into the amygdala. J Neurosci 12:854-63.

Fanselow MS, Kim JJ. 1994. Acquisition of contextual Pavlovian fear conditioning is blocked by application of an NMDA receptor antagonist D,L-2-amino-5-phosphonovaleric acid to the basolateral amygdala. Behav Neurosci 108:210-2.

Fendt M. 2001. Injections of the NMDA receptor antagonist aminophosphonopentanoic acid into the lateral nucleus of the amygdala block the expression of fear-potentiated startle and freezing. J Neurosci 21:4111-5.

Fendt M, Endres T, Apfelbach R. 2003. Temporary inactivation of the bed nucleus of the stria terminalis but not of the amygdala blocks freezing induced by trimethylthiazoline, a component of fox feces. J Neurosci 23:23-8.

Fendt M, Fanselow MS. 1999. The neuroanatomical and neurochemical basis of conditioned fear. Neurosci Biobehav Rev 23:743-60.

Gale GD, Anagnostaras SG, Godsil BP, Mitchell S, Nozawa T, Sage JR, and others. 2004. Role of the basolateral amygdala in the storage of fear memories across the adult lifetime of rats. J Neurosci 24:3810-5.

Goosens KA, Hobin JA, Maren S. 2003. Auditory-evoked spike firing in the lateral amygdala and Pavlovian fear conditioning: mnemonic code or fear bias? Neuron 40:1013-22.

Goosens KA, Holt W, Maren S. 2000. A role for amygdaloid PKA and $\mathrm{PKC}$ in the acquisition of long-term conditional fear memories in rats. Behav Brain Res 114:145-52.

Goosens KA, Maren S. 2001. Contextual and auditory fear conditioning are mediated by the lateral, basal, and central amygdaloid nuclei in rats. Learn Mem 8:148-55.

Goosens KA, Maren S. 2002. Long-term potentiation as a substrate for memory: evidence from studies of amygdaloid plasticity and Pavlovian fear conditioning. Hippocampus 12:592-9.

Goosens KA, Maren S. 2003. Pretraining NMDA receptor blockade in the basolateral complex, but not the central nucleus, of the amygdala prevents savings of conditional fear. Behav Neurosci 117:738-50.

Goosens KA, Maren S. 2004. NMDA receptors are essential for the acquisition, but not expression, of conditional fear and associative spike firing in the lateral amygdala. Eur J Neurosci 20:537-48.

Harris JA, Jones ML, Bailey GK, Westbrook RF. 2000. Contextual control over conditioned responding in an extinction paradigm. J Exp Psychol Anim Behav Process 26:174-85.

Hawkins RD, Kandel ER. 1984. Is there a cell-biological alphabet for simple forms of learning? Psychol Rev 91:375-91.

Heinbockel T, Pape HC. 2000. Input-specific long-term depression in the lateral amygdala evoked by theta frequency stimulation. J Neurosci 20:RC68.

Helmstetter FJ. 1992. Contribution of the amygdala to learning and performance of conditional fear. Physiol Behav 51:1271-6.

Helmstetter FJ, Bellgowan PS. 1994. Effects of muscimol applied to the basolateral amygdala on acquisition and expression of contextual fear conditioning in rats. Behav Neurosci 108:1005-9.

Hitchcock J, Davis M. 1986. Lesions of the amygdala, but not of the cerebellum or red nucleus, block conditioned fear as measured with the potentiated startle paradigm. Behav Neurosci 100:11-22. 
Hobin JA, Goosens KA, Maren S. 2003. Context-dependent neuronal activity in the lateral amygdala represents fear memories after extinction. J Neurosci 23:8410-6.

Impey S, Smith DM, Obrietan K, Donahue R, Wade C, Storm DR. 1998. Stimulation of cAMP response element (CRE)-mediated transcription during contextual learning. Nat Neurosci 1:595-601.

Jarrell TW, Romanski LM, Gentile CG, McCabe PM, Schneiderman N. 1986. Ibotenic acid lesions in the medial geniculate region prevent the acquisition of differential Pavlovian conditioning of bradycardia to acoustic stimuli in rabbits. Brain Res 382:199-203.

Josselyn SA, Shi CJ, Carlezon WA, Neve RL, Nestler EJ, Davis M. 2001. Long-term memory is facilitated by cAMP response element-binding protein overexpression in the amygdala. $\mathrm{J}$ Neurosci 21:2404-12.

Kapp BS, Frysinger RC, Gallagher M, Haselton JR. 1979. Amygdala central nucleus lesions: effect on heart rate conditioning in the rabbit. Physiol Behav 23:1109-17.

Kellicutt MH, Schwartzbaum JS. 1963. Formation of a conditioned emotional response (CER) following lesions of the amygdaloid complex in rats. Psychol Rep 12:351-8.

Killcross S, Robbins TW, Everitt BJ. 1997. Different types of fearconditioned behaviour mediated by separate nuclei within amygdala. Nature (Lond) 388:377-80.

Kluver H, Bucy PC. 1937. "Psychic blindness" and other symptoms following bilateral temporal lobectomy in rhesus monkeys. Am J Physiol 119:352-3.

Krapivinsky G, Krapivinsky L, Manasian Y, Ivanov A, Tyzio R, Pellegrino C, and others. 2003. The NMDA receptor is coupled to the ERK pathway by a direct interaction between NR2B and RasGRF1. Neuron 40:775-84.

LaBar KS, Gatenby JC, Gore JC, LeDoux JE, Phelps EA. 1998. Human amygdala activation during conditioned fear acquisition and extinction: a mixed-trial fMRI study. Neuron 20:937-45.

LaBar KS, LeDoux JE, Spencer DD, Phelps EA. 1995. Impaired fear conditioning following unilateral temporal lobectomy in humans. J Neurosci 15:6846-55.

Lanuza E, Nader K, Ledoux JE. 2004. Unconditioned stimulus pathways to the amygdala: effects of posterior thalamic and cortical lesions on fear conditioning. Neuroscience 125:305-15.

LeDoux JE. 2000. Emotion circuits in the brain. Annu Rev Neurosci 23:155-84.

LeDoux JE, Cicchetti P, Xagoraris A, Romanski LM. 1990. The lateral amygdaloid nucleus: sensory interface of the amygdala in fear conditioning. J Neurosci 10:1062-9.

LeDoux JE, Farb C, Ruggiero DA. 1990. Topographic organization of neurons in the acoustic thalamus that project to the amygdala. J Neurosci 10:1043-54.

LeDoux JE, Iwata J, Cicchetti P, Reis DJ. 1988. Different projections of the central amygdaloid nucleus mediate autonomic and behavioral correlates of conditioned fear. J Neurosci 8:2517-29.

LeDoux JE, Sakaguchi A, Reis DJ. 1984. Subcortical efferent projections of the medial geniculate nucleus mediate emotional responses conditioned to acoustic stimuli. J Neurosci 4:683-98.

Lee H, Kim JJ. 1998. Amygdalar NMDA receptors are critical for new fear learning in previously fear-conditioned rats. J Neurosci 18:8444-54.

Lee Y, Walker D, Davis M. 1996. Lack of a temporal gradient of retrograde amnesia following NMDA-induced lesions of the basolateral amygdala assessed with the fear-potentiated startle paradigm. Behav Neurosci 110:836-9.

Li XF, Phillips R, LeDoux JE. 1995. NMDA and non-NMDA receptors contribute to synaptic transmission between the medial geniculate body and the lateral nucleus of the amygdala. Exp Brain Res 105:87-100.

Lin $\mathrm{CH}$, Yeh $\mathrm{SH}$, Lin $\mathrm{CH}$, Lu KT, Leu TH, Chang WC, and others. 2001. A role for the PI-3 kinase signaling pathway in fear conditioning and synaptic plasticity in the amygdala. Neuron 31:841-51.

Lin CH, Yeh SH, Lu HY, Gean PW. 2003. The similarities and diversities of signal pathways leading to consolidation of conditioning and consolidation of extinction of fear memory. J Neurosci 23:8310-7.
Lindquist DH, Brown TH. 2004. Amygdalar NMDA receptors control the expression of associative reflex facilitation and three other conditional responses. Behav Neurosci 118:36-52.

Lu KT, Walker DL, Davis M. 2001. Mitogen-activated protein kinase cascade in the basolateral nucleus of amygdala is involved in extinction of fear-potentiated startle. J Neurosci 21:RC162.

Maren S. 1996. Synaptic transmission and plasticity in the amygdala: an emerging physiology of fear conditioning circuits. Mol Neurobiol 13:1-22.

Maren S. 1998. Overtraining does not mitigate contextual fear conditioning deficits produced by neurotoxic lesions of the basolateral amygdala. J Neurosci 18:3088-97.

Maren S. 1999a. Long-term potentiation in the amygdala: a mechanism for emotional learning and memory. Trends Neurosci 22:561-7.

Maren S. 1999b. Neurotoxic basolateral amygdala lesions impair learning and memory but not the performance of conditional fear in rats. J Neurosci 19:8696-703.

Maren S. 2000. Auditory fear conditioning increases CS-elicited spike firing in lateral amygdala neurons even after extensive overtraining. Eur J Neurosci 12:4047-54.

Maren S. 2001. Neurobiology of Pavlovian fear conditioning. Annu Rev Neurosci 24:897-931.

Maren S, Aharonov G, Fanselow MS. 1996. Retrograde abolition of conditional fear after excitotoxic lesions in the basolateral amygdala of rats: absence of a temporal gradient. Behav Neurosci 110:718-26.

Maren S, Aharonov G, Stote DL, Fanselow MS. 1996. N-methyl-Daspartate receptors in the basolateral amygdala are required for both acquisition and expression of conditional fear in rats. Behav Neurosci 110:1365-74.

Maren S, Baudry M. 1995. Properties and mechanisms of long-term synaptic plasticity in the mammalian brain: relationships to learning and memory. Neurobiol Learn Mem 63:1-18.

Maren S, Fanselow MS. 1995. Synaptic plasticity in the basolateral amygdala induced by hippocampal formation stimulation in vivo. $\mathrm{J}$ Neurosci 15:7548-64.

Maren S, Fanselow MS. 1996. The amygdala and fear conditioning: has the nut been cracked? Neuron 16:237-40.

Maren S, Ferrario CR, Corcoran KA, Desmond TJ, Frey KA. 2003. Protein synthesis in the amygdala, but not the auditory thalamus, is required for consolidation of Pavlovian fear conditioning in rats. Eur J Neurosci 18:3080-8.

Maren S, Holt W. 2000. The hippocampus and contextual memory retrieval in Pavlovian conditioning. Behav Brain Res 110:97-108.

Maren S, Yap SA, Goosens KA. 2001. The amygdala is essential for the development of neuronal plasticity in the medial geniculate nucleus during auditory fear conditioning in rats. J Neurosci 21:RC135

Martin SJ, Grimwood PD, Morris RG. 2000. Synaptic plasticity and memory: an evaluation of the hypothesis. Annu Rev Neurosci 23:649-711.

McDonald AJ. 1998. Cortical pathways to the mammalian amygdala. Prog Neurobiol 55:257-332.

McGaugh JL. 2004. The amygdala modulates the consolidation of memories of emotionally arousing experiences. Annu Rev Neurosci 27:1-28.

McHugh SB, Deacon RM, Rawlins JN, Bannerman DM. 2004. Amygdala and ventral hippocampus contribute differentially to mechanisms of fear and anxiety. Behav Neurosci 118:63-78.

McKernan MG, Shinnick-Gallagher P. 1997. Fear conditioning induces a lasting potentiation of synaptic currents in vitro. Nature (Lond) 390:607-11

Meunier M, Bachevalier J, Murray EA, Malkova L, Mishkin M. 1999. Effects of aspiration versus neurotoxic lesions of the amygdala on emotional responses in monkeys. Eur J Neurosci 11:4403-18.

Milad MR, Quirk GJ. 2002. Neurons in medial prefrontal cortex signal memory for fear extinction. Nature 420:70-4.

Miserendino MJ, Sananes CB, Melia KR, Davis M. 1990. Blocking of acquisition but not expression of conditioned fear-potentiated star- 
tle by NMDA antagonists in the amygdala. Nature (Lond) 345:716-8.

Morgan MA, LeDoux JE. 1995. Differential contribution of dorsal and ventral medial prefrontal cortex to the acquisition and extinction of conditioned fear in rats. Behav Neurosci 109:681-8.

Morris JS, Dolan RJ. 2004. Dissociable amygdala and orbitofrontal responses during reversal fear conditioning. Neuroimage 22:372-80

Morris JS, Ohman A, Dolan RJ. 1998. Conscious and unconscious emotional learning in the human amygdala. Nature 393:467-70.

Myers KM, Davis M. 2002. Behavioral and neural analysis of extinction. Neuron 36:567-84.

Nader K, Majidishad P, Amorapanth P, LeDoux JE. 2001. Damage to the lateral and central, but not other, amygdaloid nuclei prevents the acquisition of auditory fear conditioning. Learn Mem 8:156-63.

Nader K, Schafe GE, Le Doux JE. 2000. Fear memories require protein synthesis in the amygdala for reconsolidation after retrieval. Nature 406:722-6.

Ohman A, Mineka S. 2001. Fears, phobias, and preparedness: toward an evolved module of fear and fear learning. Psychol Rev 108:483-522.

O'Reilly RC, Rudy JW. 2001. Conjunctive representations in learning and memory: principles of cortical and hippocampal function. Psychol Rev 108:311-45.

Pare D, Collins DR. 2000. Neuronal correlates of fear in the latera amygdala: multiple extracellular recordings in conscious cats. J Neurosci 20:2701-10.

Pare D, Quirk GJ, Ledoux JE. 2004. New vistas on amygdala networks in conditioned fear. J Neurophysiol 92:1-9.

Pavlov IP. 1927. Conditioned reflexes: an investigation of the physiological activity of the cerebral cortex. London: Oxford University Press.

Pitkanen A, Savander V, LeDoux JE. 1997. Organization of intraamygdaloid circuitries in the rat: an emerging framework for understanding functions of the amygdala. Trends Neurosci 20:517-23

Poremba A, Gabriel M. 2001. Amygdalar efferents initiate auditory thalamic discriminative training-induced neuronal activity. J Neurosci 21:270-8

Quirk G. 2001. Learning not fear: prefrontal-amygdala circuits involved in extinction learning. Integr Physiol Behav Sci 36:323.

Quirk GJ, Armony JL, LeDoux JE. 1997. Fear conditioning enhances different temporal components of tone-evoked spike trains in auditory cortex and lateral amygdala. Neuron 19:613-24.

Quirk GJ, Likhtik E, Pelletier JG, Pare D. 2003. Stimulation of media prefrontal cortex decreases the responsiveness of central amygdala output neurons. J Neurosci 23:8800-7.

Quirk GJ, Repa C, LeDoux JE. 1995. Fear conditioning enhances short-latency auditory responses of lateral amygdala neurons: parallel recordings in the freely behaving rat. Neuron 15:1029-39.

Quirk GJ, Russo GK, Barron JL, Lebron K. 2000. The role of ventromedial prefrontal cortex in the recovery of extinguished fear. J Neurosci 20:6225-31.

Repa JC, Muller J, Apergis J, Desrochers TM, Zhou Y, LeDoux JE. 2001. Two different lateral amygdala cell populations contribute to the initiation and storage of memory. Nat Neurosci 4:724-31.

Rodrigues SM, Farb CR, Bauer EP, LeDoux JE, Schafe GE. 2004. Pavlovian fear conditioning regulates Thr286 autophosphorylation of $\mathrm{Ca} 2+/$ calmodulin-dependent protein kinase II at lateral amygdala synapses. J Neurosci 24:3281-8.

Rodrigues SM, Schafe GE, LeDoux JE. 2002. Intra-amygdala blockade of the NR2B subunit of the NMDA receptor disrupts the acquisition but not the expression of fear conditioning. J Neurosci 22:U1-U2.

Rogan MT, LeDoux JE. 1995. LTP is accompanied by commensurate enhancement of auditory-evoked responses in a fear conditioning circuit. Neuron 15:127-36

Rogan MT, Staubli UV, LeDoux JE. 1997. Fear conditioning induces associative long-term potentiation in the amygdala. Nature (Lond) 390:604-7.
Romanski LM, Clugnet MC, Bordi F, LeDoux JE. 1993. Somatosensory and auditory convergence in the lateral nucleus of the amygdala. Behav Neurosci 107:444-50.

Rosenkranz JA, Moore H, Grace AA. 2003. The prefrontal cortex regulates lateral amygdala neuronal plasticity and responses to previously conditioned stimuli. J Neurosci 23:11054-64

Royer S, Martina M, Pare D. 1999. An inhibitory interface gates impulse traffic between the input and output stations of the amygdala. J Neurosci 19:10575-83.

Royer S, Pare D. 2003. Conservation of total synaptic weight through balanced synaptic depression and potentiation. Nature 422:518-22.

Sanders MJ, Wiltgen BJ, Fanselow MS. 2003. The place of the hippocampus in fear conditioning. Eur J Pharmacol 463:217-23.

Santini E, Ge H, Ren K, Pena de Ortiz S, Quirk GJ. 2004. Consolidation of fear extinction requires protein synthesis in the medial prefrontal cortex. J Neurosci 24:5704-10.

Schafe GE, Atkins CM, Swank MW, Bauer EP, Sweatt JD, LeDoux JE. 2000. Activation of ERK/MAP kinase in the amygdala is required for memory consolidation of Pavlovian fear conditioning. J Neurosci 20:8177-87.

Schafe GE, LeDoux JE. 2000. Memory consolidation of auditory Pavlovian fear conditioning requires protein synthesis and protein kinase A in the amygdala. J Neurosci 20:RC96.

Schafe GE, Nader K, Blair HT, LeDoux JE. 2001. Memory consolidation of Pavlovian fear conditioning: a cellular and molecular perspective. Trends Neurosci 24:540-6.

Shumyatsky GP, Tsvetkov E, Malleret G, Vronskaya S, Hatton M, Hampton L, and others. 2002. Identification of a signaling network in lateral nucleus of amygdala important for inhibiting memory specifically related to learned fear. Cell 111:905-18.

Swanson LW, Petrovich GD. 1998. What is the amygdala? Trends Neurosci 21:323-31.

Thomas GM, Huganir RL. 2004. MAPK cascade signalling and synaptic plasticity. Nat Rev Neurosci 5:173-83.

Thompson RF. 1988. The neural basis of basic associative learning of discrete behavioral responses. Trends Neurosci 11:152-5.

Treit D, Menard J. 1997. Dissociations among the anxiolytic effects of septal, hippocampal, and amygdaloid lesions. Behav Neurosci 111:653-8.

Tsvetkov E, Carlezon WA, Benes FM, Kandel ER, Bolshakov VY. 2002. Fear conditioning occludes LTP-induced presynaptic enhancement of synaptic transmission in the cortical pathway to the lateral amygdala. Neuron 34:289-300.

Vazdarjanova A, McGaugh JL. 1998. Basolateral amygdala is not critical for cognitive memory of contextual fear conditioning. Proc Natl Acad Sci U S A 95:15003-7.

Walker DL, Davis M. 2000. Involvement of NMDA receptors within the amygdala in short- versus long-term memory for fear conditioning as assessed with fear-potentiated startle. Behav Neurosci 114:1019-33.

Walker DL, Ressler KJ, Lu KT, Davis M. 2002. Facilitation of conditioned fear extinction by systemic administration or intra-amygdala infusions of D-cycloserine as assessed with fear-potentiated startle in rats. J Neurosci 22:2343-51.

Wallace KJ, Rosen JB. 2001. Neurotoxic lesions of the lateral nucleus of the amygdala decrease conditioned fear but not unconditioned fear of a predator odor: Comparison with electrolytic lesions. J Neurosci 21:3619-27.

Weiskrantz L. 1956. Behavioral changes associated with ablation of the amygdaloid complex in monkeys. J Comp Physiol Psychol 49:381-91.

Wilensky AE, Schafe GE, LeDoux JE. 1999. Functional inactivation of the amygdala before but not after auditory fear conditioning prevents memory formation. J Neurosci 19:RC48.

Yaniv D, Schafe GE, LeDoux JE, Richter-Levin G. 2001. A gradient of plasticity in the amygdala revealed by cortical and subcortical stimulation, in vivo. Neuroscience 106:613-20.

Zinebi F, Xie J, Liu J, Russell RT, Gallagher JP, McKernan MG, and others. 2003. NMDA currents and receptor protein are downregulated in the amygdala during maintenance of fear memory. J Neurosci 23:10283-91. 